\title{
Plastin Family of Actin-Bundling Proteins: Its Functions in Leukocytes, Neurons, Intestines, and Cancer
}

\author{
Hiroto Shinomiya \\ Department of Immunology and Host Defenses, Ehime University Graduate School of Medicine, Toon, Ehime 791-0295, Japan \\ Correspondence should be addressed to Hiroto Shinomiya, hiroto@m.ehime-u.ac.jp
}

Received 19 July 2011; Revised 29 September 2011; Accepted 4 October 2011

Academic Editor: Liza Pon

Copyright (c) 2012 Hiroto Shinomiya. This is an open access article distributed under the Creative Commons Attribution License, which permits unrestricted use, distribution, and reproduction in any medium, provided the original work is properly cited.

Sophisticated regulation of the actin cytoskeleton by a variety of actin-binding proteins is essential for eukaryotic cells to perform their diverse functions. The plastin (also know, as fimbrin) protein family belongs to actin-bundling proteins, and the protein family is evolutionarily conserved and expressed in yeast, plant, and animal cells. Plastins are characterized by EF-hand Ca ${ }^{2+}$ binding domains and actin-binding domains and can cross-link actin filaments into higher-order assemblies like bundles. Three isoforms have been identified in mammals. T-plastin is expressed in cells from solid tissues, such as neurons in the brain. I-plastin expression is restricted to intestine and kidney; the isoform plays a vital role in the function of absorptive epithelia in these organs. L-plastin is expressed in hematopoietic cell lineages and in many types of cancer cells; the isoform is thus considered to be a useful biomarker for cancer.

\section{Introduction}

Dynamics of the actin cytoskeleton is one of the cardinal features of eukaryotic cells, which is essential for fundamental cellular functions such as cell division, intracellular traffic of organelles, cell morphology, and cell motility [1]. The architecture of the actin cytoskeleton is regulated by a variety of proteins termed actin-binding proteins [1]. Actin filaments are organized into two types of arrays: bundles and weblike networks. Likewise, the actin filaments crosslinking proteins that help to stabilize and maintain these distinct structures are divided into two classes: bundling proteins and web-forming proteins. The plastin (also known as fimbrin) protein family belongs to bundling proteins and is evolutionarily conserved from yeast to mammalian cells. In mammals, three isoforms are known to be expressed in a celltype-specific manner and exhibit distinct properties (Table 1 and Figure 1). In this paper, studies regarding the structure and biological functions of plastins are reviewed.

\section{Structure of Plastins}

The structure of plastins is well conserved from lower eukaryotes to humans and is characterized by actin binding domains (ABD). An ABD consists of a pair of $\sim 125$ residue calponin-homology $(\mathrm{CH})$ domains (Figure $2(\mathrm{a})$ ). $\mathrm{ABD}$-containing proteins include proteins such as spectrin, $\alpha$-actinin, dystrophin, cortexillin, and plastin/fimbrin [2] . The plastins are unique among these, as they possess two tandem repeats of $\mathrm{ABD}(\mathrm{ABD} 1$ and $\mathrm{ABD} 2)$ within a single polypeptide chain and cross-link actin filaments into higher order assemblies like bundles through this tandem pair of ABDs [3]. N-terminal EF-hand $\mathrm{Ca}^{2+}$-binding domains (Figure 2(a)) are also important, since the actin bundling activity of plastins is regulated by $\mathrm{Ca}^{2+}[4]$.

Though ABD1 was previously solved by X-ray crystallography [5], the complete crystal structure of plastins has not yet been resolved. We have recently performed conformational analyses of murine L-plastin by X-ray scattering in solution and for the first time shown the overall structure of full-length plastin protein by reconstructing from data using the DAMMIN program (Figure 2(b)) [6]. The program DAMMIN is an advanced modeling procedure designed to reconstruct the shape of a molecule from the scattering intensity of small angle X-ray scattering data. Our results, taken together with those by Klein et al. on the plastin core region [7], demonstrated that plastin has a compact globular structure rather than a dumbbell-like shape and that the two 
TABLE 1: Plastin isoforms expressed in distinct cell types.

\begin{tabular}{lc}
\hline Isoforms & Cell/tissue types \\
\hline I-plastin (Plastin 1) & Intestine and kidney \\
L-plastin (Plastin 2) & Leukocytes and cancer \\
T-plastin (Plastin 3) & Solid tissues \\
\hline
\end{tabular}

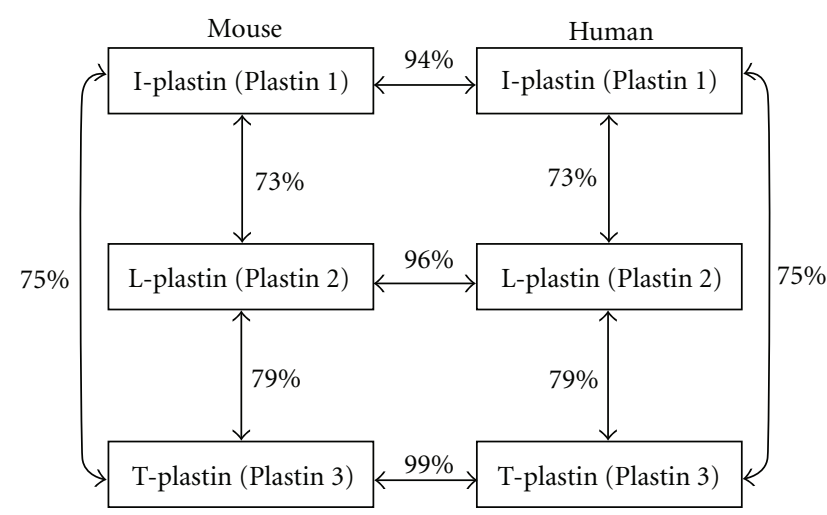

Figure 1: Human and mouse plastin isoforms. The homology between the amino acid sequences of these isoforms is showed.

$\mathrm{ABDs}$ are packed together in an approximately antiparallel arrangement with the $\mathrm{N}$ - and $\mathrm{C}$-terminal $\mathrm{CH}$ domains $(\mathrm{CH} 1$ and $\mathrm{CH} 4$ ) making direct contact (Figure 2(c)). We also demonstrated that significant conformational changes of the protein were induced in the presence of $\mathrm{Ca}^{2+}[6]$. These findings should shed light on the molecular mechanisms of how plastins regulate the architecture of actin filaments.

\section{Functions of Plastin Isoforms}

Since plastins are expressed in a cell-type-specific manner, it is conceivable that the most suitable isoform is expressed to regulate the actin cytoskeleton in a particular type of cell. Functions of plastin isoforms in distinct types of cells or tissues in mammals are reviewed.

3.1. Plastin Functions in Leukocytes. We isolated a 65$\mathrm{kDa}$ cytosolic protein that was phosphorylated in murine macrophages by stimulation with bacterial lipopolysaccharide (LPS) and determined its complete primary structure as a novel protein $[8-10]$. The sequence of the $65-\mathrm{kDa}$ protein revealed that it was a murine homolog of human L-plastin that had been identified as a transformationinduced polypeptide of neoplastic human fibroblasts [11]. We further demonstrated that L-plastin plays an important role in macrophage functions such as host defense against bacterial infections [12-15]. We, and others, have clarified that L-plastin is exclusively expressed in leukocytes such as lymphocytes, macrophages, and granulocytes under physiological conditions. Representative studies addressing the role of L-plastin in leukocyte functions are shown in Table 2 $[8-10,12-39]$; the isoform serves important functions not only in cells of innate immunity such as macrophages and

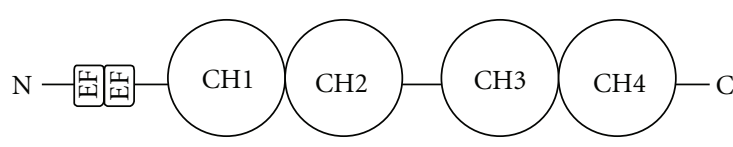

$\mathrm{ABD} 1$

$\mathrm{ABD} 2$

(a)

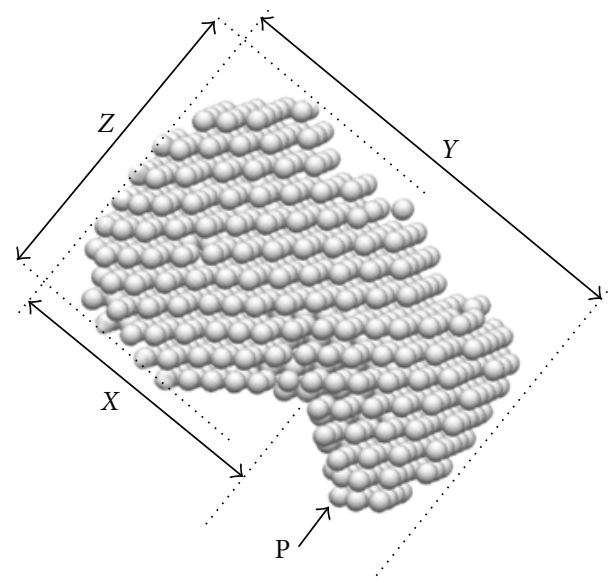

(b)

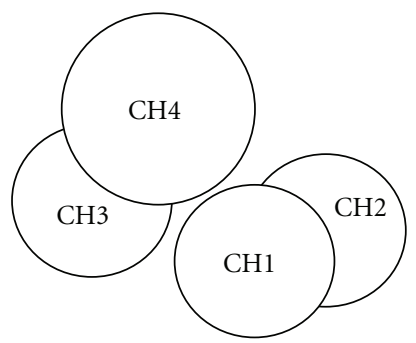

(c)

FIGURE 2: Schematic diagram of L-plastin structure. (a) Domain organization of L-plastin. The protein possesses an N-terminal headpiece of $\sim 100$ amino acids containing two EF-hand $\mathrm{Ca}^{2+}$ binding motifs and two actin-binding domains (ABDs) consisting of $\mathrm{ABD} 1$ (residues 120-379) and ABD2 (residues 394-623), and each $\mathrm{ABD}$ contains two calponin-homology $(\mathrm{CH})$ domains. (b) Reconstructed molecular shape of L-plastin. Conformational analyses of L-plastin by X-ray scattering in solution revealed that plastin has a compact globular structure rather than a dumbbelllike shape. It is conceivable that the two ABDs are packed together in an approximately antiparallel arrangement with the $\mathrm{N}$ - and $\mathrm{C}$ terminal $\mathrm{CH}$ domains $(\mathrm{CH} 1$ and $\mathrm{CH} 4)$ making direct contact as shown in Figure 2(c); that is, $X, Y$, and $Z$ correspond to $\mathrm{CH} 1-\mathrm{CH} 3$, $\mathrm{CH} 2-\mathrm{CH} 4$, and $\mathrm{CH} 3-\mathrm{CH} 4$ of the plastin protein, respectively. $P$ indicates a putative $\mathrm{N}$-terminal headpiece. See more details in $[6,7]$. (c) Possible arrangement of the ABDs $(\mathrm{CH} 1-\mathrm{CH} 4)$ of L-plastin in solution without $\mathrm{Ca}^{2+}$.

granulocytes (neutrophils and eosinophils) [8-10, 12-29], but also in those of adaptive immunity such as $\mathrm{T}$ and $\mathrm{B}$ lymphocytes [30-37].

Many of the studies have addressed the phosphorylation of L-plastin during leukocyte activation by various stimuli (Table 2). Only L-plastin has, so far, been known to be phosphorylated in cells among three isoforms. We demonstrated that L-plastin was phosphorylated exclusively on Ser5 in 
TABLE 2: Studies on L-plastin in leukocytes.

\begin{tabular}{|c|c|c|}
\hline Leukocyte types & Key words of the study & References \\
\hline \multicolumn{3}{|l|}{ Innate immunity } \\
\hline Macrophages & Bacterial lipopolysaccharide (LPS)-induced activation & {$[8-10,12]^{*},[13,14]$} \\
\hline Macrophages & Grancalcin and host defence & {$[15]$} \\
\hline Macrophages & IL-1/TNF-induced activation & {$[16]^{*}$} \\
\hline Macrophages & Podosome formation & {$[17]$} \\
\hline Macrophages & Zebrafish and lineage marker & {$[18-20]$} \\
\hline Macrophages & Toxoplasma gondii-infection & {$[21]$} \\
\hline Neutrophils & IL-8-induced activation & {$[22]^{*}$} \\
\hline Neutrophils & Fc receptor and phagocytosis & {$[23,24]^{*}$} \\
\hline Neutrophils & L-plastin $\mathrm{KO}^{\#}$ and integrin & {$[25,26]^{*}$} \\
\hline Eosinophils & GM-CSF-induced priming & {$[27]^{*}$} \\
\hline Osteoclasts & Podosome formation & {$[28]$} \\
\hline Osteoclasts & Sealing ring formation & {$[29]$} \\
\hline \multicolumn{3}{|l|}{ Adaptive immunity } \\
\hline T-cells & IL-2-induced activation & {$[30]^{*}$} \\
\hline T-cells & Accessory receptors & {$[31]^{*}$} \\
\hline T-cells & Lymphokine-activated killer cells & {$[32]^{*}$} \\
\hline T-cells & Costimulation & {$[33]^{*}$} \\
\hline T-cells & CCR7 and thymus & {$[34]$} \\
\hline T-cells & LFA- 1 and immune synapse & {$[35]$} \\
\hline T-cells & L-plastin $\mathrm{KO}^{\#}$ and impaired $\mathrm{T}$ cell responses & {$[36]$} \\
\hline B-cells & Marginal zone B cell development & {$[37]$} \\
\hline \multicolumn{3}{|c|}{ Suppression immunotherapies targeting L-plastin } \\
\hline Leukocytes & Cannabinoid receptor agonists & {$[38]$} \\
\hline Leukocytes & Glucocorticoid dexamethasone & {$[39]$} \\
\hline
\end{tabular}

* These studies addressed the L-plastin phosphorylation in leukocytes.

\#Disruption of the L-plastin gene in mice.

macrophages by stimulation with LPS [10]. In connection with this, Jones et al. showed that the Ser5-phosphorylated Lplastin peptide induced adhesion in neutrophils [25]. It was also demonstrated that phosphorylation on Ser5 increased the F-actin-binding activity of L-plastin and promoted its targeting to sites of actin assembly in cells [40]. In addition to phosphorylation, the actin-bundling action of L-plastin is also regulated by intracellular $\mathrm{Ca}^{2+}$ [4]. The above findings indicate that L-plastin regulates the actin cytoskeleton in a phosphorylation- and/or $\mathrm{Ca}^{2+}$-dependent manner. These features of L-plastin seem to help leukocytes rapidly rearrange their actin cytoskeleton when they need to quickly respond to a variety of extracellular stimuli. Indeed, it has recently been demonstrated by using L-plastin gene-disrupted mice that neutrophils lacking L-plastin are deficient in killing bacterial pathogens [26] and that $\mathrm{T}$ and $\mathrm{B}$ cell functions are also impaired in the mice; $\mathrm{T}$ cell responses to antigens are impaired [36], and splenic maturation of B cells and an antibody response to Streptococcus pneumoniae are largely diminished [37].

These studies regarding the key roles of L-plastin in leukocytes functions may provide the basis for new therapy. Several suppression immunotherapies targeting L-plastin have been proposed (Table 2) [38, 39]. Cannabinoid CB2 receptor-specific compounds were found to inhibit the Lplastin phosphorylation in human monocytes and blocked experimental autoimmune encephalomyelitis in the rat [38]. In addition, it has recently been shown that glucocorticoid dexamethasone inhibits the L-plastin phosphorylation in human $\mathrm{T}$ cells, which prevents the immune synapse formation and subsequent $\mathrm{T}$ cell activation [39].

3.2. Plastin Functions in Neurons. The nervous system chiefly expresses T-plastin among the three isoforms. Though microglia in the brain are a kind of resident macrophage, their expression of L-plastin is very low under physiological conditions (unpublished observations). With regard to Tplastin in neurons, an interesting article has recently been published; the authors showed that high expression of $\mathrm{T}$ plastin acts as a protective modifier of spinal muscular atrophy (SMA), the most frequent genetic cause of early childhood lethality, and that T-plastin is important for axonogenesis, as its overexpression rescues the axon length and outgrowth defects in neurons of the SMA mouse [41]. Therefore, T-plastin seems to play a vital role in neuronal differentiation. Another interesting study addressed the 
preventive role of T-plastin in neurodegenerative diseases, demonstrating that T-plastin lessens the toxicity of polyglutamine proteins in neurons, such as ataxin and huntingtin, that cause neurodegenerative disorder [42]. These, and related studies, are summarized in Table 3 [41-43].

Since sensory cells are closely related to the nervous system, studies regarding the plastin expression in sensory cells are reviewed here as shown in Table 3. Several studies using specific antibodies against plastins/fimbrin revealed that the proteins are expressed in the stereocilia of auditory hair cells in the chicken and mammals [44-47], suggesting that plastins may contribute to the physiological auditory sense. In the rat cochlear hair cells, T- and I-plastin, but not L-plastin, were found to be expressed [47]. T-plastin is expressed only in the early stage of hair cell differentiation, while I-plastin is constantly expressed from the early to the adult stages, indicating that I-plastin is the major isoform expressed in the adult cochlear hair cells. The architecture of actin filaments cross-linked by plastins may be essential for the transduction of auditory signals by cochlear hair cells.

3.3. Plastin Functions in the Intestine. The first protein of the plastin/fimbrin family was discovered in microvilli of the chicken intestinal brush border and named fimbrin [48]. Chicken fimbrin was characterized as a cytoskeletal protein that binds and cross-links F-actin filaments $[49,50]$. Meanwhile, a third plastin isoform, named I-plastin, was identified in humans and was found to be expressed in the small intestine, colon, and kidney [51]. Thus, I-plastin is considered to be the human homolog of chicken fimbrin. Using I-plastin gene-disrupted mice, it has recently been reported that a lack of I-plastin results in increased fragility of the intestinal epithelium and decreased transepithelial resistance [52], suggesting that I-plastin is an important regulator of brush border morphology and stability. Recently, a model of the microvillar cytoskeleton of the brush border that includes plastin/fimbrin cross-linking actin filaments has been proposed [53]. These studies are summarized in Table 4 [48-53].

3.4. Plastin Functions in Cancer. The cell-type-specific expression of plastin isoforms is strictly regulated under physiological conditions. However, ectopic expression of plastins in malignant cells has been observed in many studies as shown in Table $5[11,54-69]$. L-plastin that is normally expressed only in hematopoietic cells is especially expressed in a variety of cancer cells of nonhematopoietic origin. Lin et al. demonstrated that $68 \%$ of cancers derived from epithelia express L-plastin [54]. It was further clarified by using sensitive RT-PCR that the L-plastin gene is activated in most human cancer cells [56]. Thus, L-plastin has been considered to be a common marker of many types of human cancer. In particular, a high percentage of cancer cells arising from female reproductive tissues express Lplastin constitutively and abundantly though its expression is ovarian steroid hormone-independent in cancer cells [58]. In addition, the expression of L-plastin in prostatic epithelial cells is linked to the malignant state, and once expressed in
TABLE 3: Studies on plastins in the nervous system and sensory cells.

\begin{tabular}{lc}
\hline Key words of the study & References \\
\hline T-plastin in neurons & \\
Spinal muscular atrophy and axonogenesis & {$[41,43]$} \\
Spinocerebellar ataxia and polyglutamine protein & {$[42]$} \\
Plastin/fimbrin in sensory cells & \\
Fimbrin, chicken, stereocilia, auditory hair cells & {$[44,45]$} \\
I-plastin, mouse/rat, auditory hair cells & {$[46,47]$} \\
\hline
\end{tabular}

TABLE 4: Studies on fimbrin/I-plastin in the intestine.

\begin{tabular}{lc}
\hline Key words of the study & References \\
\hline Fimbrin, Microvilli & {$[48]$} \\
Intestinal brush border & {$[49,50]$} \\
I-plastin, Intestine, Kidney & {$[51]$} \\
I-plastin KO , Intestinal epithelium & {$[52]$} \\
Model of microvillar cytoskeleton & {$[53]$} \\
\hline
\end{tabular}

${ }^{\#}$ Disruption of the I-plastin gene in mice.

carcinoma, its expression is regulated by steroid hormone receptors [59]. The L-plastin gene promoter was found to include several hormone receptor-responsive elements [55, 57]. These evidences support a trans-activation mechanism for the activation of L-plastin synthesis accompanying tumorigenesis. In contrast, T-plastin gene expression was found to be suppressed in human colorectal cancer cells, suggesting that downregulation of T-plastin is involved in cancer development [65].

Since L-plastin is normally expressed in leukocytes that are able to move rapidly to infectious and inflammatory sites, cancer cells may gain the ability to metastasize to other parts of the body by expressing L-plastin. In other words, Lplastin tends to be expressed in freely movable cells such as leukocytes and cancer cells. On the other hand, it was found that T-plastin is expressed in certain types of malignant cells of leukocyte origin, including cutaneous $\mathrm{T}$ cell lymphoma and Sezary syndrome (Table 5) [66-69]. In cutaneous T cell lymphoma, dense clusters or nodules of malignant cells are observed [70]; these cells appear to lose their motility. This seems to contrast sharply with the case of cancer cells that express L-plastin. Considering the above, the expression of plastin isoforms could be dysregulated when cells, regardless of their origin, become malignant, which may endow tumor cells with properties distinct from those of their normal counterparts.

On the basis of these observations regarding abnormal expression of plastins, clinical applications have been developed. Cancer screening and diagnosis methods assessing the expression of plastins as a biomarker have been described. These include choroids plexus tumors, urinary bladder cancer, ovarian cancer, and colorectal cancer (Table 5) [7174]. Furthermore, gene therapy experiments targeting the L-plastin gene or L-plastin promoters in cancer cells have been started, as shown in Table 5 [75-78]. These approaches have shown promising results. For example, Peng et al. 
TABLE 5: Studies on plastins in cancer cells.

\begin{tabular}{lc}
\hline Key words of the study & References \\
\hline Ectopic expression of L-plastin in cancer & {$[11]$} \\
Transformed human fibroblasts & {$[54]$} \\
Many types of human cancer & {$[55-57]$} \\
L-plastin gene promoter in cancer & {$[58]$} \\
Ovarian steroid hormones & {$[59]$} \\
Prostate cancer and steroid hormone & {$[60]$} \\
Chromosome translocation & {$[61]$} \\
Breast cancer and expression pattern & {$[62]$} \\
Colorectal cancer and metastasis & {$[63]$} \\
Colon cancer, invasion, and loss of E-cadherin & {$[64]$} \\
Melanoma tumor invasion & {$[65]$} \\
T-plastin downregulation and CpG methylation & \\
Ectopic expression of T-plastin in lymphoma & {$[66,67]$} \\
Cutaneous T cell lymphoma & {$[68,69]$} \\
Sezary cells & \\
As a biomarker for cancer screening and diagnosis & {$[71]$} \\
Choroid plexus tumors and diagnostic marker & {$[72]$} \\
Bladder cancer and biomarker & {$[73]$} \\
Proteomics imaging and mass spectrometry & {$[74]$} \\
Colorectal cancer and human feces & {$[75-77]$} \\
Gene therapies targeting L-plastin gene & {$[78]$} \\
L-plastin promoter and gene therapy & \\
Antisense L-plastin gene and tumor suppression & \\
\hline
\end{tabular}

prepared adenoviral vectors in which a truncated human L-plastin promoter and the cytosine deaminase $(C D)$ gene were coinserted [76]. $C D$ is a bacterial gene which converts 5-fluorocytosine (5FC: nontoxic to cells) to 5-fluorouracil (5FU: toxic to most cells). When the vector is transfected into human ovarian or bladder cancer cells in vitro, CD transcription is increased through the L-plastin promoter activation, leading to tumor cell death via the conversion of $5 \mathrm{FC}$ to $5 \mathrm{FU}$ in the cells. The authors also performed in vivo study and demonstrated that human tumor masses grown in nude mice were reduced by this method [76]. In another study by Zheng et al., the authors constructed retroviral vectors to express regions of the human L-plastin gene in antisense orientation and found that introduction of the vectors into prostate carcinoma cells reduced the growth rates of the cells and suppressed their invasion and motility in vitro [78]. This suggests that overexpression of L-plastin is involved in cancer invasion and metastasis and that downregulation of L-plastin by antisense delivery is potentially a useful approach to interfere with prostate cancer progression.

\section{Perspectives}

Since plastins are evolutionarily conserved and expressed in yeast, plant, and animal cells, they should play a fundamental role in cellular activities. Sophisticated regulation of the actin cytoskeleton seems to be a mandatory event for the functions of eukaryotic cells. It has been investigated in detail how plastins interact with actin filaments in vitro. Extensive studies have clarified that three plastin isoforms are expressed in distinct types of cells in mammals and that dysregulated expression of plastins appears to be important in the progression of various cancers. As described in this paper, plastins can serve as versatile regulators of the actin cytoskeleton in many aspects of cellular functions. Further studies will be expected to reveal how plastins, together with other actin-binding proteins, dynamically regulate the remodeling of cytoskeletal architecture during diverse cellular activities.

\section{Abbreviations}

ABD: Actin binding domain

$\mathrm{CH}$ : Calponin-homology

IL: Interleukin

LPS: Bacterial lipopolysaccharide

SMA: Spinal muscular atrophy

TNF: Tumor necrosis factor.

\section{Acknowledgment}

This work was supported by Grant-in-Aid for Scientific Research (C). No conflict of interests is present.

\section{References}

[1] T. D. Pollard and J. A. Cooper, "Actin, a central player in cell shape and movement," Science, vol. 326, no. 5957, pp. 12081212, 2009.

[2] S. Bañuelos, M. Saraste, and K. D. Carugo, "Structural comparisons of calponin homology domains: implications for actin binding," Structure, vol. 6, no. 11, pp. 1419-1431, 1998.

[3] M. V. de Arruda, S. Watson, C. S. Lin, J. Leavitt, and P. Matsudaira, "Fimbrin is a homologue of the cytoplasmic phosphoprotein plastin and has domains homologous with calmodulin and actin gelation proteins," Journal of Cell Biology, vol. 111, no. 3, pp. 1069-1079, 1990.

[4] Y. Namba, M. Ito, Y. Zu, K. Shigesada, and K. Maruyama, "Human T cell L-plastin bundles actin filaments in a calcium dependent manner," Journal of Biochemistry, vol. 112, no. 4, pp. 503-507, 1992.

[5] S. C. Goldsmith, N. Pokala, W. Shen, A. A. Fedorov, P. Matsudaira, and S. C. Almo, "The structure of an actincrosslinking domain from human fimbrin," Nature Structural Biology, vol. 4, no. 9, pp. 708-712, 1997.

[6] H. Shinomiya, M. Shinjo, L. Fengzhi, Y. Asano, and H. Kihara, "Conformational analysis of the leukocyte-specific EFhand protein p65/L-plastin by X-ray scattering in solution," Biophysical Chemistry, vol. 131, no. 1-3, pp. 36-42, 2007.

[7] M. G. Klein, W. Shi, U. Ramagopal et al., "Structure of the actin crosslinking core of fimbrin," Structure, vol. 12, no. 6, pp. 999-1013, 2004.

[8] H. Shinomiya, H. Hirata, and M. Nakano, "Purification and characterization of the $65-\mathrm{kDa}$ protein phosphorylated in murine macrophages by stimulation with bacterial lipopolysaccharide," Journal of Immunology, vol. 146, no. 10, pp. 3617-3625, 1991. 
[9] H. Shinomiya, H. Hirata, S. Saito, H. Yagisawa, and M. Nakano, "Identification of the $65-\mathrm{kDa}$ phosphoprotein in murine macrophages as a novel protein: homology with human L-plastin," Biochemical and Biophysical Research Communications, vol. 202, no. 3, pp. 1631-1638, 1994.

[10] H. Shinomiya, A. Hagi, M. Fukuzumi, M. Mizobuchi, H. Hirata, and S. Utsumi, "Complete primary structure and phosphorylation site of the 65-kDa macrophage protein phosphorylated by stimulation with bacterial lipopolysaccharide," Journal of Immunology, vol. 154, no. 7, pp. 3471-3478, 1995.

[11] C. S. Lin, R. H. Aebersold, S. B. Kent, M. Varma, and J. Leavitt, "Molecular cloning and characterization of plastin, a human leukocyte protein expressed in transformed human fibroblasts," Molecular and Cellular Biology, vol. 8, no. 11, pp. 4659-4668, 1988.

[12] A. Hagi, H. Hirata, and H. Shinomiya, "Analysis of a bacterial lipopolysaccharide-activated serine kinase that phosphorylates p65/L-plastin in macrophages," Microbiology and Immunology, vol. 50, no. 4, pp. 331-335, 2006.

[13] H. Shinomiya, K. Nagai, H. Hirata et al., "Preparation and characterization of recombinant murine p65/L-plastin expressed in Escherichia coli and high-titer antibodies against the protein," Bioscience, Biotechnology and Biochemistry, vol. 67, no. 6, pp. 1368-1375, 2003.

[14] K. Toyooka, F. Liu, M. Ishii et al., "Generation and characterization of monoclonal antibodies that specifically recognize p65/L-plastin isoform but not T-plastin isoform," Bioscience, Biotechnology and Biochemistry, vol. 70, no. 6, pp. 1402-1407, 2006.

[15] F. Liu, H. Shinomiya, T. Kirikae, H. Hirata, and Y. Asano, "Characterization of murine grancalcin specifically expressed in leukocytes and its possible role in host defense against bacterial infection," Bioscience, Biotechnology and Biochemistry, vol. 68, no. 4, pp. 894-902, 2004.

[16] M. Shiroo and K. Matsushima, "Enhanced phosphorylation of 65 and $74 \mathrm{kDa}$ proteins by tumor necrosis factor and interleukin-1 in human peripheral blood mononuclear cells," Cytokine, vol. 2, no. 1, pp. 13-20, 1990.

[17] J. G. Evans, I. Correia, O. Krasavina, N. Watson, and P. Matsudaira, "Macrophage podosomes assemble at the leading lamella by growth and fragmentation," Journal of Cell Biology, vol. 161, no. 4, pp. 697-705, 2003.

[18] P. Herbomel, B. Thisse, and C. Thisse, "Ontogeny and behaviour of early macrophages in the zebrafish embryo," Development, vol. 126, no. 17, pp. 3735-3745, 1999.

[19] P. Herbomel, B. Thisse, and C. Thisse, "Zebrafish early macrophages colonize cephalic mesenchyme and developing brain, retina, and epidermis through a M-CSF receptordependent invasive process," Developmental Biology, vol. 238, no. 2, pp. 274-288, 2001.

[20] J. R. Mathias, M. E. Dodd, K. B. Walters, S. K. Yoo, E. A. Ranheim, and A. Huttenlocher, "Characterization of zebrafish larval inflammatory macrophages," Developmental and Comparative Immunology, vol. 33, no. 11, pp. 1212-1217, 2009.

[21] D. H. Zhou, Z. G. Yuan, F. R. Zhao et al., "Modulation of mouse macrophage proteome induced by Toxoplasma gondii tachyzoites in vivo," Parasitology Research, vol. 109, no. 6, pp. 1637-1646, 2011.

[22] M. Shibata, Y. Yamakawa, T. Ohoka, S. Mizuno, and K. Suzuki, "Characterization of a 64-kd protein phosphorylated during chemotactic activation with IL-8 and fMLP of human polymorphonuclear leukocytes. II. Purification and amino acid analysis of phosphorylated 64-kd protein," Journal of Leukocyte Biology, vol. 54, no. 1, pp. 10-16, 1993.

[23] S. L. Jones and E. J. Brown, "Fc $\gamma$ RII-mediated adhesion and phagocytosis induce L-plastin phosphorylation in human neutrophils," The Journal of Biological Chemistry, vol. 271, no. 24, pp. 14623-14630, 1996.

[24] J. Wang and E. J. Brown, "Immune complex-induced integrin activation and L-plastin phosphorylation require protein kinase A," The Journal of Biological Chemistry, vol. 274, no. 34, pp. 24349-24356, 1999.

[25] S. L. Jones, J. Wang, C. W. Turck, and E. J. Brown, "A role for the actin-bundling protein L-plastin in the regulation of leukocyte integrin function," Proceedings of the National Academy of Sciences of the United States of America, vol. 95, no. 16, pp. 9331-9336, 1998.

[26] H. Chen, A. Mocsai, H. Zhang et al., "Role for plastin in host defense distinguishes integrin signaling from cell adhesion and spreading," Immunity, vol. 19, no. 1, pp. 95-104, 2003.

[27] K. Pazdrak, T. W. Young, C. Straub, S. Stafford, and A. Kurosky, "Priming of eosinophils by GM-CSF is mediated by protein kinase CbII-phosphorylated L-plastin," Journal of Immunology, vol. 186, no. 11, pp. 6485-6496, 2011.

[28] S. G. Babb, P. Matsudaira, M. Sato, I. Correia, and S. S. Lim, "Fimbrin in podosomes of monocyte-derived osteoclasts," Cell Motility and the Cytoskeleton, vol. 37, no. 4, pp. 308-325, 1997.

[29] T. Ma, K. Sadashivaiah, N. Madayiputhiya, and M. A. Chellaiah, "Regulation of sealing ring formation by L-plastin and cortactin in osteoclasts," The Journal of Biological Chemistry, vol. 285, no. 39, pp. 29911-29924, 2010.

[30] Y. Zu, K. Shigesada, E. Nishida et al., “65-kilodalton protein phosphorylated by interleukin 2 stimulation bears two putative actin-binding sites and two calcium-binding sites," Biochemistry, vol. 29, no. 36, pp. 8319-8324, 1990.

[31] S. W. Henning, S. C. Meuer, and Y. Samstag, "Serine phosphorylation of a $67-\mathrm{kDa}$ protein in human $\mathrm{T}$ lymphocytes represents an accessory receptor-mediated signaling event," Journal of Immunology, vol. 152, no. 10, pp. 4808-4815, 1994.

[32] M. J. Frederick, L. V. Rodriguez, D. A. Johnston, B. G. Darnay, and E. A. Grimm, "Characterization of the $\mathrm{Mr}$ 65,000 lymphokine-activated killer proteins phosphorylated after tumor target binding: evidence that pp65a and pp65b are phosphorylated forms of L-plastin," Cancer Research, vol. 56, no. 1, pp. 138-144, 1996.

[33] G. H. Wabnitz, T. Köcher, P. Lohneis et al., "Costimulation induced phosphorylation of L-plastin facilitates surface transport of the T cell activation molecules CD69 and CD25," European Journal of Immunology, vol. 37, no. 3, pp. 649-662, 2007.

[34] S. C. Morley, C. Wang, W. L. Lo et al., "The actin-bundling protein L-plastin dissociates CCR7 proximal signaling from CCR7-induced motility," Journal of Immunology, vol. 184, no. 7, pp. 3628-3638, 2010.

[35] G. H. Wabnitz, P. Lohneis, H. Kirchgessner et al., "Sustained LFA-1 cluster formation in the immune synapse requires the combined activities of L-plastin and calmodulin," European Journal of Immunology, vol. 40, no. 9, pp. 2437-2449, 2010.

[36] W. Chen, S. C. Morley, D. Donermeyer et al., "Actinbundling protein L-plastin regulates T cell activation," Journal of Immunology, vol. 185, no. 12, pp. 7487-7497, 2010.

[37] E. M. Todd, L. E. Deady, and S. C. Morley, "The actinbundling protein L-plastin is essential for marginal zone B cell development," Journal of Immunology, vol. 187, no. 6, pp. 3015-3025, 2011. 
[38] C. A. Lunn, E. P. Reich, J. S. Fine et al., "Biology and therapeutic potential of cannabinoid CB2 receptor inverse agonists," British Journal of Pharmacology, vol. 153, no. 2, pp. 226-239, 2008.

[39] G. H. Wabnitz, F. Michalke, C. Stober et al., "L-plastin phosphorylation: a novel target for the immunosuppressive drug dexamethasone in primary human T-cells," European Journal of Immunology, vol. 41, no. 11, pp. 3157-3169, 2011.

[40] B. Janji, A. Giganti, V. De Corte et al., "Phosphorylation on Ser5 increases the F-actin-binding activity of L-plastin and promotes its targeting to sites of actin assembly in cells," Journal of Cell Science, vol. 119, no. 9, pp. 1947-1960, 2006.

[41] G. E. Oprea, S. Kröber, M. L. McWhorter et al., "Plastin 3 is a protective modifier of autosomal recessive spinal muscular atrophy," Science, vol. 320, no. 5875, pp. 524-527, 2008.

[42] M. Ralser, U. Nonhoff, M. Albrecht et al., "Ataxin-2 and huntingtin interact with endophilin-A complexes to function in plastin-associated pathways," Human Molecular Genetics, vol. 14, no. 19, pp. 2893-2909, 2005.

[43] M. Bowerman, C. L. Anderson, A. Beauvais, P. P. Boyl, W. Witke, and R. Kothary, "SMN, profilin IIa and plastin 3: a link between the deregulation of actin dynamics and SMA pathogenesis," Molecular and Cellular Neuroscience, vol. 42, no. 1, pp. 66-74, 2009.

[44] D. Drenckhahn, K. Engel, D. Hofer, C. Merte, L. Tilney, and M. Tilney, "Three different actin filament assemblies occur in every hair cell: each contains a specific actin crosslinking protein," Journal of Cell Biology, vol. 112, no. 4, pp. 641-651, 1991.

[45] K. H. Lee and D. A. Cotanche, "Localization of the hair-cellspecific protein fimbrin during regeneration in the chicken cochlea," Audiology and Neuro-Otology, vol. 1, no. 1, pp. 4153, 1996.

[46] P. Lawlor, W. Marcotti, M. N. Rivolta, C. J. Kros, and M. C. Holley, "Differentiation of mammalian vestibular hair cells from conditionally immortal, postnatal supporting cells," Journal of Neuroscience, vol. 19, no. 21, pp. 9445-9458, 1999.

[47] N. Daudet and M. C. Lebart, "Transient expression of the T-isoform of plastins/fimbrin in the stereocilia of developing auditory hair cells," Cell Motility and the Cytoskeleton, vol. 53, no. 4, pp. 326-336, 2002.

[48] A. Bretscher and K. Weber, "Fimbrin, a new microfilamentassociated protein present in microvilli and other cell surface structures," Journal of Cell Biology, vol. 86, no. 1, pp. 335-340, 1980.

[49] A. Bretscher, "Purification of an 80,000 -dalton protein that is a component of the isolated microvillus cytoskeleton, and its localization in nonmuscle cells," Journal of Cell Biology, vol. 97, no. 2, pp. 425-432, 1983.

[50] M. B. Heintzelman and M. S. Mooseker, "Assembly of the brush border cytoskeleton: changes in the distribution of microvillar core proteins during enterocyte differentiation in adult chicken intestine," Cell Motility and the Cytoskeleton, vol. 15, no. 1, pp. 12-22, 1990.

[51] C. S. Lin, W. Shen, Z. P. Chen, Y. H. Tu, and P. Matsudaira, "Identification of I-plastin, a human fimbrin isoform expressed in intestine and kidney," Molecular and Cellular Biology, vol. 14, no. 4, pp. 2457-2467, 1994.

[52] E. M. S. Grimm-Günter, C. Revenu, S. Ramos et al., "Plastin 1 binds to keratin and is required for terminal web assembly in the intestinal epithelium," Molecular Biology of the Cell, vol. 20, no. 10, pp. 2549-2562, 2009.
[53] J. W. Brown and C. J. McKnight, "Molecular model of the microvillar cytoskeleton and organization of the brush border," PLoS ONE, vol. 5, no. 2, Article ID e9406, 2010.

[54] C. S. Lin, T. Park, Z. P. Chen, and J. Leavitt, "Human plastin genes. Comparative gene structure, chromosome location, and differential expression in normal and neoplastic cells," The Journal of Biological Chemistry, vol. 268, no. 4, pp. 2781-2792, 1993.

[55] C. S. Lin, Z. P. Chen, T. Park, K. Ghosh, and J. Leavitt, "Characterization of the human L-plastin gene promoter in normal and neoplastic cells," The Journal of Biological Chemistry, vol. 268, no. 4, pp. 2793-2801, 1993.

[56] T. Park, Z. P. Chen, and J. Leavitt, "Activation of the leukocyte plastin gene occurs in most human cancer cells," Cancer Research, vol. 54, no. 7, pp. 1775-1781, 1994.

[57] C. S. Lin, A. Lau, C. C. Yeh, C. H. Chang, and T. F. Lue, "Upregulation of L-plastin gene by testosterone in breast and prostate cancer cells: identification of three cooperative androgen receptor-binding sequences," DNA and Cell Biology, vol. 19, no. 1, pp. 1-7, 2000.

[58] J. Leavitt, Z. P. Chen, C. J. Lockwood, and F. Schatz, "Regulation of synthesis of the transformation-induced protein, leukocyte plastin, by ovarian steroid hormones," Cancer Research, vol. 54, no. 13, pp. 3447-3454, 1994.

[59] J. Zheng, N. Rudra-Ganguly, G. J. Miller, K. A. Moffatt, R. J. Cote, and P. Roy-Burman, "Steroid hormone induction and expression patterns of L-plastin in normal and carcinomatous prostate tissues," American Journal of Pathology, vol. 150, no. 6, pp. 2009-2018, 1997.

[60] S. Galiègue-Zouitina, S. Quief, M. P. Hildebrand et al., "Nonrandom fusion of L-plastin(LCP1) and LAZ3(BCL6) genes by $\mathrm{t}(3 ; 13)$ ( $\mathrm{q} 27 ; \mathrm{q} 14)$ chromosome translocation in two cases of B-cell non-Hodgkin lymphoma," Genes Chromosomes and Cancer, vol. 26, no. 2, pp. 97-105, 1999.

[61] A. Lapillonne, O. Coué, E. Friederich et al., "Expression patterns of L-plastin isoform in normal and carcinomatous breast tissues," Anticancer Research, vol. 20, no. 5, pp. 31773182, 2000.

[62] M. Otsuka, M. Kato, T. Yoshikawa et al., "Differential expression of the L-plastin gene in human colorectal cancer progression and metastasis," Biochemical and Biophysical Research Communications, vol. 289, no. 4, pp. 876-881, 2001.

[63] E. Foran, P. McWilliam, D. Kelleher, D. T. Croke, and A. Long, "The leukocyte protein L-plastin induces proliferation, invasion and loss of E-cadherin expression in colon cancer cells," International Journal of Cancer, vol. 118, no. 8, pp. 20982104, 2006.

[64] M. Klemke, M. T. Rafael, G. H. Wabnitz et al., "Phosphorylation of ectopically expressed L-plastin enhances invasiveness of human melanoma cells," International Journal of Cancer, vol. 120, no. 12, pp. 2590-2599, 2007.

[65] Y. Sasaki, F. Itoh, T. Kobayashi et al., "Increased expression of T-fimbrin gene after DNA damage in $\mathrm{CHO}$ cells and inactivation of T-fimbrin by CPG methylation in human colorectal cancer cells," International Journal of Cancer, vol. 97, no. 2, pp. 211-216, 2002.

[66] L. Kari, A. Loboda, M. Nebozhyn et al., "Classification and prediction of survival in patients with the leukemic phase of cutaneous T cell lymphoma," Journal of Experimental Medicine, vol. 197, no. 11, pp. 1477-1488, 2003.

[67] E. Capriotti, E. C. Vonderheid, C. J. Thoburn, M. Wasik, D. W. Bahler, and A. D. Hess, "Expression of T-plastin, FoxP3 
and other tumor-associated markers by leukemic T-cells of cutaneous T-cell lymphoma," Leukemia and Lymphoma, vol. 49, no. 6, pp. 1190-1201, 2008.

[68] M. W. Su, I. Dorocicz, W. H. Dragowska et al., "Aberrant expression of T-plastin in sezary cells," Cancer Research, vol. 63, no. 21, pp. 7122-7127, 2003.

[69] N. Tang, H. Gibson, T. Germeroth, P. Porcu, H. W. Lim, and H. K. Wong, "T-plastin (PLS3) gene expression differentiates Sézary syndrome from mycosis fungoides and inflammatory skin diseases and can serve as a biomarker to monitor disease progression," British Journal of Dermatology, vol. 162, no. 2, pp. 463-466, 2010.

[70] R. Hussain and A. Bajoghli, "Primary cutaneous CD30positive large $\mathrm{T}$ cell lymphoma in an 80-year-old man: a case report," ISRN Dermatology, vol. 2011, Article ID 634042, pp. $1-3,2011$.

[71] M. Hasselblatt, C. Böhm, L. Tatenhorst et al., "Identification of novel diagnostic markers for choroid plexus tumors: a microarray-based approach," American Journal of Surgical Pathology, vol. 30, no. 1, pp. 66-74, 2006.

[72] L. D. Harris, J. De La Cerda, T. Tuziak et al., "Analysis of the expression of biomarkers in urinary bladder cancer using a tissue microarray," Molecular Carcinogenesis, vol. 47, no. 9, pp. 678-685, 2008.

[73] S. Kang, H. S. Shim, J. S. Lee et al., "Molecular proteomics imaging of tumor interfaces by mass spectrometry," Journal of Proteome Research, vol. 9, no. 2, pp. 1157-1164, 2010.

[74] C. S. Ang and E. C. Nice, "Targeted in-gel MRM: a hypothesis driven approach for colorectal cancer biomarker discovery in human feces," Journal of Proteome Research, vol. 9, no. 9, pp. 4346-4355, 2010.

[75] I. Chung, P. E. Schwartz, R. G. Crystal, G. Pizzorno, J. Leavitt, and A. B. Deisseroth, "Use of L-plastin promoter to develop an adenoviral system that confers transgene expression in ovarian cancer cells but not in normal mesothelial cells," Cancer Gene Therapy, vol. 6, no. 2, pp. 99-106, 1999.

[76] X. Y. Peng, J. H. Won, T. Rutherford et al., "The use of the L-plastin promoter for adenoviral-mediated, tumor-specific gene expression in ovarian and bladder cancer cell lines," Cancer Research, vol. 61, no. 11, pp. 4405-4413, 2001.

[77] H. Akbulut, L. Zhang, Y. Tang, and A. Deisseroth, "Cytotoxic effect of replication-competent adenoviral vectors carrying L-plastin promoter regulated E1A and cytosine deaminase genes in cancers of the breast, ovary and colon," Cancer Gene Therapy, vol. 10, no. 5, pp. 388-395, 2003.

[78] J. Zheng, N. Rudra-Ganguly, W. C. Powell, and P. RoyBurman, "Suppression of prostate carcinoma cell invasion by expression of antisense L-plastin gene," American Journal of Pathology, vol. 155, no. 1, pp. 115-122, 1999. 

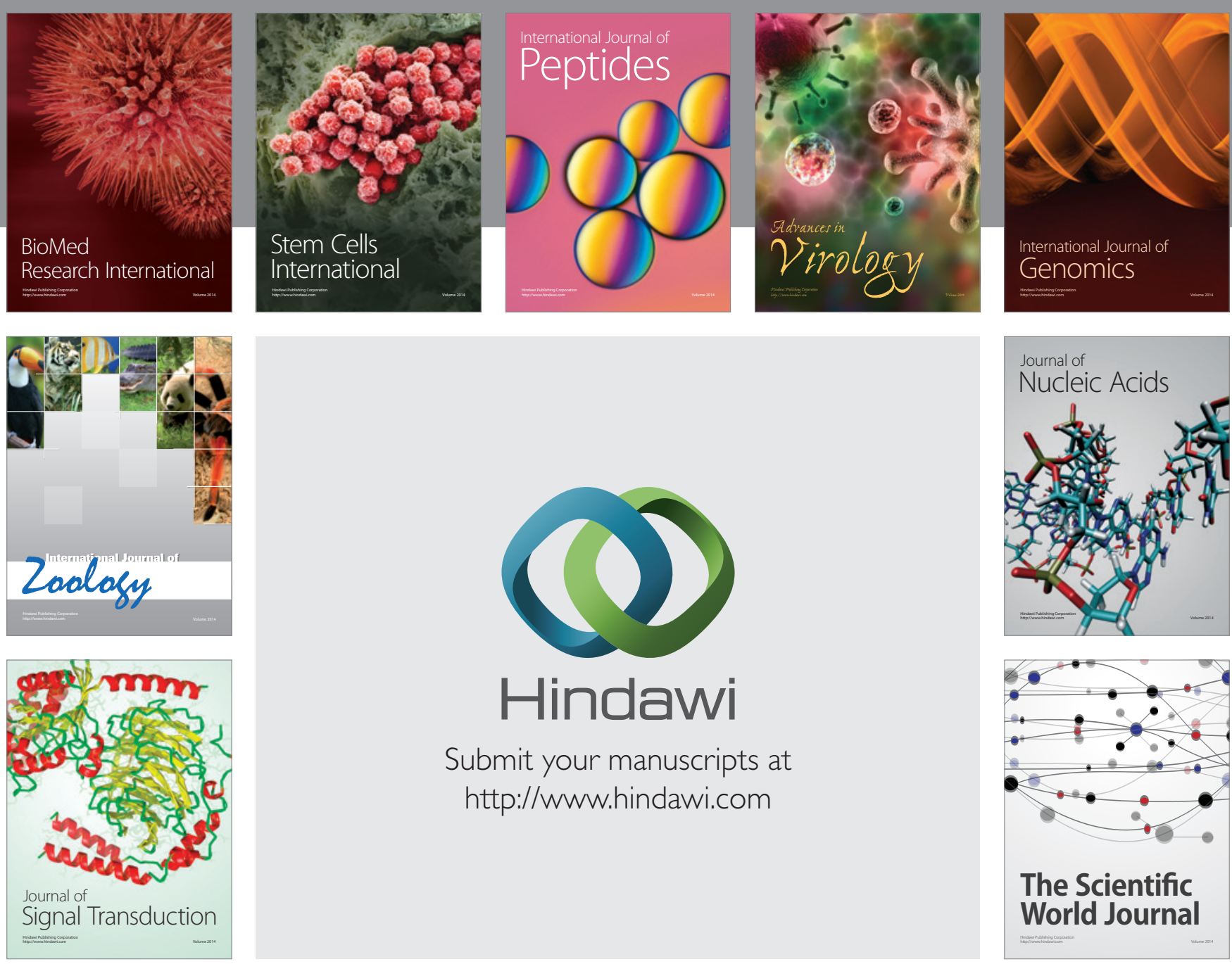

Submit your manuscripts at

http://www.hindawi.com
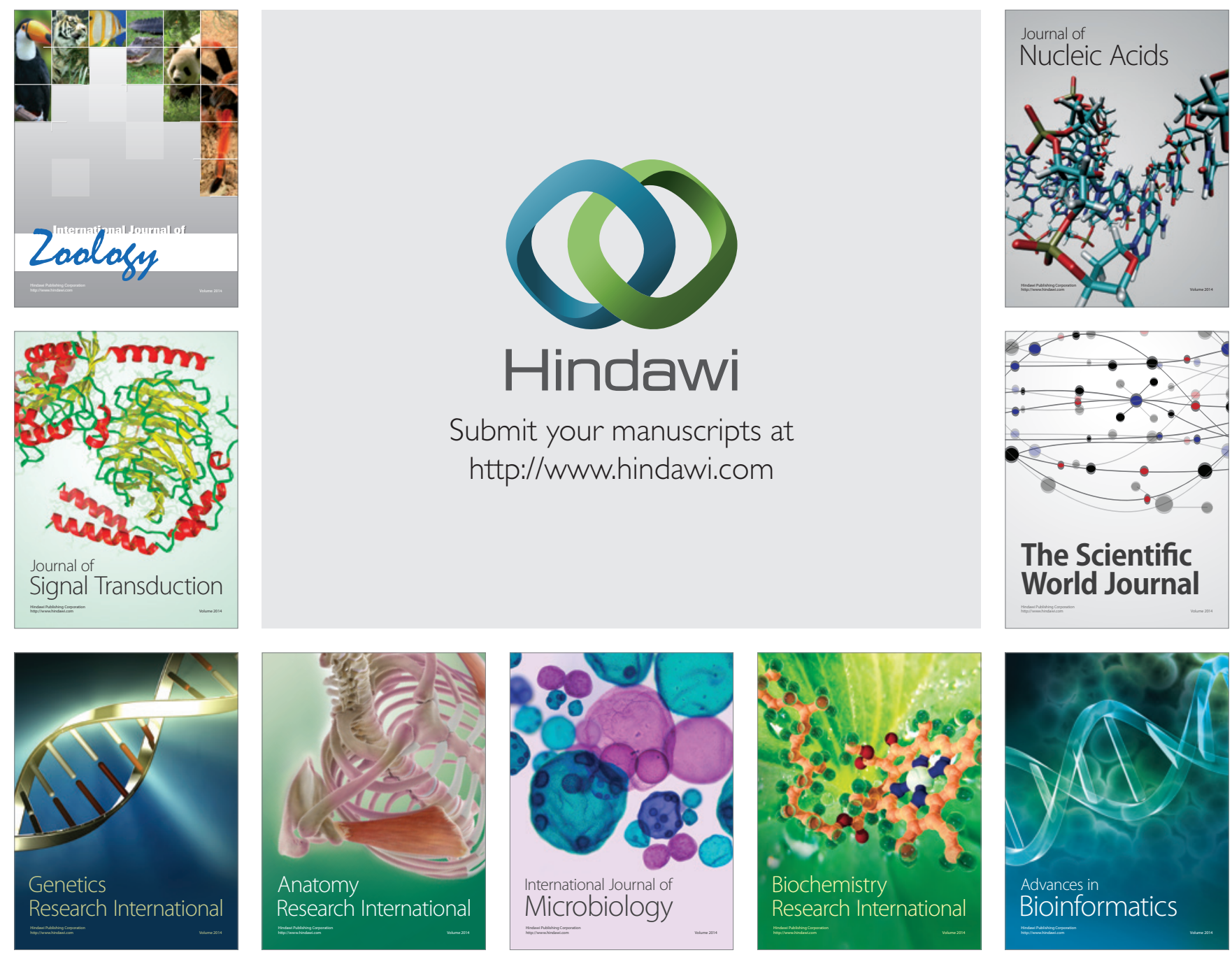

The Scientific World Journal
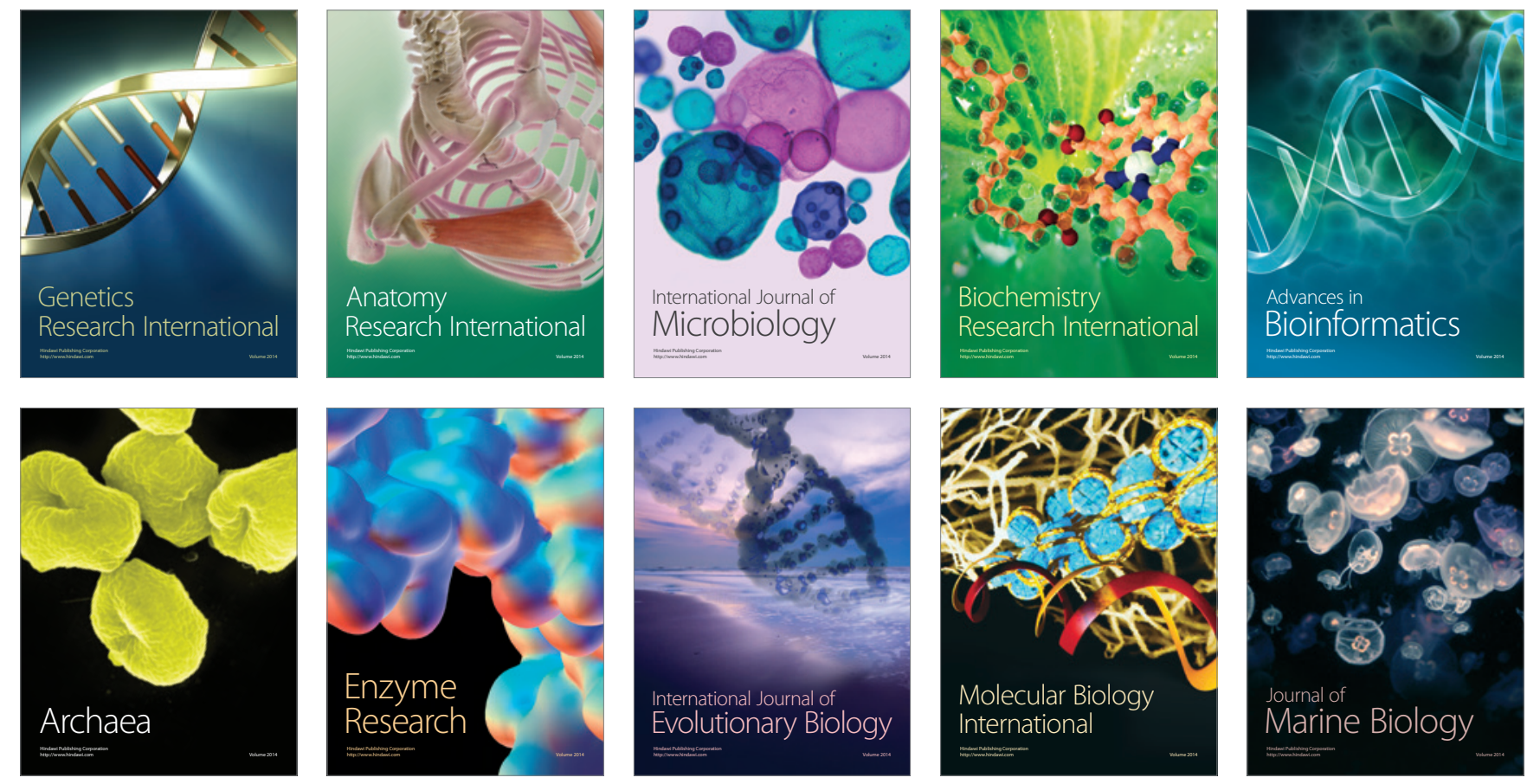